\title{
Defining the digital workplace: a systematic literature review
}

\author{
Ljubiša Mićić \\ University of Banja Luka, Faculty of Economics, Banja Luka, Bosnia and Herzegovina \\ https://orcid.org/0000-0002-2879-5760
}

Homayoun Khamooshi

George Washington University, School of Business, Washington, DC, United States of America

https://orcid.org/0000-0003-4507-4540

\section{Lazar Raković}

University of Novi Sad, Faculty of Economics in Subotica, Subotica, Serbia

https://orcid.org/0000-0002-1465-588X

\section{Predrag Matković}

University of Novi Sad, Faculty of Economics in Subotica, Subotica, Serbia https://orcid.org/0000-0002-9956-0088

\begin{abstract}
There have been a significant number of publications about digital workplace transformation. This is due to technological developments in the last decades as well as the COVID-19 pandemic. However, there is no adequate overall definition of the term. This leads to misunderstandings and confused interpretation of the digital workplace, sometimes even narrowing it down to a set of tools or a platform.

Given the complexity of digital workplace transformation, there is a need to have an integrated prospective and analyze it not just from a technological perspective, but from an organizational and processes point of view as well. Therefore, this paper is an attempt to review the concept and offer a comprehensive definition of the digital workplace. This includes all the important aspects of the transformation including tools and platforms as well as personal issues, organization, processes and management.

The paper provides a systematic literature review of the publications in leading bibliographic and citation bases, starting from Web of Science and Scopus to SpringerLink, IEEE Xplore and Association for Information Systems eLibrary. The review includes not only journal papers, but also leading proceedings, books and other referent publications. It addresses the authors' approaches, perspectives, terminologies, focusses and understanding of workplace transformation over the last decade by a comprehensive review of the state of art of the literature in the field of digital workplace. Finally, a set of recommendations are made to further research in increasingly important subject of digital workplace transformation.
\end{abstract}

\section{Keywords}

digital workplace, digital transformation, change management, systematic literature review

\section{Introduction}

Modern workplace requires not only technological but also organizational and process adaptation to achieve full functional and operational transformation from a traditional into a digital workplace. Social and technological changes have affected the ways of communication, cooperation and collaboration. Challenges and opportunities that those changes bring are discussed between policy makers, academics, businessmen and others. There are different viewpoints on how changes affect the way we do business, but it is unquestionable that technology has strong impact on work and organization. According to Coetzee (2019), in the twenty-first century "organizations 
from the era of Industry 4.0 are rapidly becoming smart networked jobs as a result of the exponential revolution brought by technological development". Dery, Sebastian and van der Meulen (2017) state that technological and organizational progress has significantly improved the communication, collaboration and coworking in conjunction with lifestyle changes and trends related to work-life balance. It enabled the digital transformation of the workplace. The focus of digital workplace transformation can be on technological tools or socalled "enablers" but it should also include organizational adjustment, changed processes and psychological factors of employees (Eckhardt, Endter, Giordano, \& Somers, 2018).

Most of contemporary research perceives the concept of digital workplace and the processes of its implementation as a multidisciplinary function. Therefore, it definitely needs to be further defined and expanded in contrast to the simplified view in science and practice. Eckhardt et al. (2018) note that the key factors in changing the modern labor market and workplace are the following:

- power has shifted from employer to employee;

- the demographics of Western economies have changed towards greater participation of the so-called Millennials in the labor force.

Among other things, the past couple of decades are recognizable by the significant development of information technologies and the changes they have brought in the field of organization and performance of work, as well as changes in the nature of work, which has been significantly accelerated by digital transformation and digital workplace design (Williams \& Schubert, 2018). Changes in technology/applications and changes in the workforce require a workplace that encourages productivity, collaboration, innovation and agility which also lowers the cost of information technology and business operations (Attaran, Attaran, \& Kirkland, 2019). In addition, digital innovations enable communication and collaboration that can lead to a change in the nature of work. Bearing in mind that work is normally a social activity and that it may require intensive communication and collaboration between employees, the significance of the abovementioned changes and their effects on jobs transformation are unquestionable (Meske \& Junglas, 2021).
All the above changes and needed adaptations impose the demand for a clear definition of digital workplace as well as its success factors, starting from the competencies and attitudes of employees to the implementation of specific tools, techniques and applications.

\section{Goals and methodology of the systematic literature review}

In this paper Systematic Literature Review (SLR) is performed following the methodology developed by Barbara Kitchenham and others in several publications (Kitchenham et al., 2009, 2010; Turner, Kitchenham, Budgen, \& Brereton, 2008). The review starts by defining the research goals and development of the research protocol, followed by identification of the key databases and papers in them based on defined keywords. Then, the review continues with the analysis, selection and quality assessment of publications. The review ends with data extractions and synthesis.

The main goal of this paper is to identify key research publications in leading bibliographical and citation bases, in order to develop a comprehensive definition of digital workplace and its transformation processes and concepts. Additionally, it defines the key success factors of the transformation process and set a direction for future research in this field.

The aim of the literature review was to identify empirical and theoretical analysis related to the digital workplace as part of the general digital transformation, but also to identify the shortcomings of current research and providing directions for the future research.

The review first defines the basic research questions on the topic of digital workplace and in accordance with that, provides comprehensive and overall digital workplace definitions that can be used by practitioners and future researchers.

\section{Source materials}

The review started with a search of journals and papers, conference proceedings, reports and other similar related scientific and professional literature in the following bibliographical and citation databases:

- Web of Science (WoS) by Clarivate Analytics,

- Scopus by Elsevier,

- Xplore by The Institute of Electrical and Electronics Engineers (IEEE) 
- Electronic library (eLibrary) by The Association for Information Systems (AIS).

Additionally, books, guides and other literature (e.g., selected papers in published monographs) were added, following the keyword rule. Those publications were extracted from the following databases: SpringerLink (EISZ) and Springer Ebook packages. The above-mentioned databases were searched by the keywords "digital workplace". Additional criteria were:

- Publications primary language must be English or German,

- The source/paper should have been published after 2010

- The paper must be peer-reviewed publication.

The first phase of literature review included search of the specific databases related to the subject of the research (subject or topic, depending on the different database) and filtered papers from journals and conferences proceedings, books and other publications. The search and review process consisted of several steps: primary results scanning, filtering of results based on title, filtering based on abstract and final selection based on the content and conclusion of the publications (Figure 1). Some of the publications have been added bearing in mind those were used as primary source in previously selected publications.

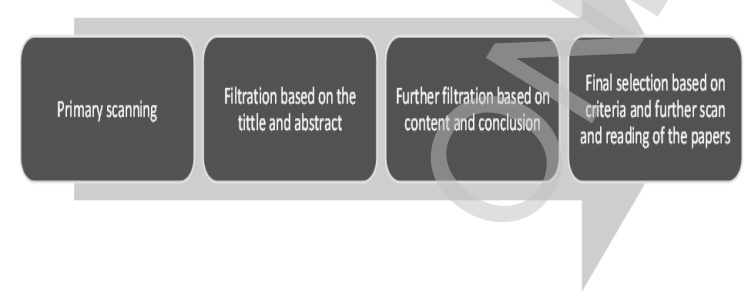

Figure 1 Literature review process Source: the authors' contribution

The primary results of the database scan included counting the publications followed by further review of the results. The first pass database search results are presented in Table 1 as numbers of "hits". Further filtering was implemented using the desktop application for quoting and filtering literature Mendeley, with the same add-in for MS Word. The application identified identical publications that occurred in more than one database.
Table 1 Quantity of the results after databases were searched by keywords

\begin{tabular}{c|c}
\hline Database & $\begin{array}{c}\text { Number of hits based on the keywords } \\
\text { "digital workplace" }\end{array}$ \\
\hline WoS & 1,401 \\
\hline Scopus & 1,643 \\
\hline IEEE Xplore & 176 \\
\hline AIS eLibrary & 2,988 \\
\hline \multicolumn{2}{c}{ Source: the authors, early spring 2021 search }
\end{tabular}

The results were further filtered in the second phase, based on several criteria: existence of keywords in the title or abstract, connection of the paper with the subject of research and whether the publication comes from a related scientific field (Figure 2).

\section{Are keywords indided in the tittle or abstract?}

Are those key words explained as a term connected to the subject of the research?

Is the publication coming from connected scientific field? (eg, medical paper are excluded)

Figure 2 Criteria for filtering publications - second phase Source: the authors

Some of the publications were in more than one database. Majority of the papers found addressed the digital workplace from an unrelated scientific viewpoint or were unrelated to the research topic. The review continued with 114 publications in the next phase, without duplicates and including books, guides and other related publications. In the third phase some of the primary sources of those 114 publications were added.

Publications are divided in three basic groups: papers from journals, papers from scientific conference proceedings and, edited books and other publications (Table 2).

Table 2 Quantity of review sources by group, second phase

\begin{tabular}{l|c}
\hline Type of source & Number \\
\hline Conference Proceedings & 37 \\
\hline Papers from scientific journals & 57 \\
\hline Edited book and other publications & 20 \\
\hline Total & 114 \\
\hline
\end{tabular}

In the next phase, we analyzed the conclusion and content of the publication for each of the following factors, in order to identify review segments:

- Subject of publication research,

- Sample size and industry selection, 
- Relation to the SLR research topic,

- Limitations of the research,

- Recommendation for the future research.

When we plot the line graph of numbers of publications per year over time, there is a clear volume increase or upward trend. Number of the publications in the period 2012- 2015 was stable. However, after 2016 and especially after 2018, growth in number of papers was significant, which suggests that research interest for this subject has been increasing in recent years (Figure 3 ).

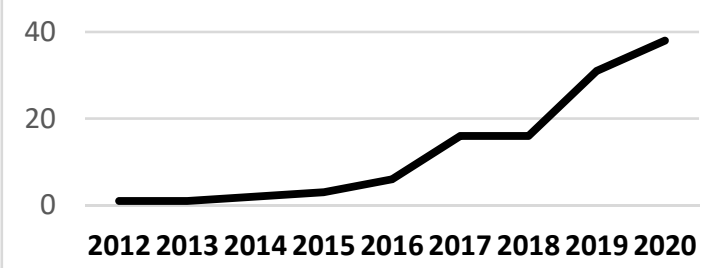

Figure 3 Number of publications per year Source: the authors

There have been fewer than ten publications in the years before 2016 compared to 31 in 2019 or 38 in 2020. Therefore, progressive growth in the number of publications was present throughout the decade and this upward trend seems to be continuous.

When we separate or dissect the change in volume of different publications over time, it becomes evident that journal papers have the most significant growth. Proceedings, after initial growth, are decreasing in total number. Books, reports and other publications have also grown which might be more correlated with increased professionals' interest in digital workplace transformation. Therefore, we can conclude that conferences directed the scientific community towards digital workplace transformation which became the topic of journal papers afterwards (Figure 4).

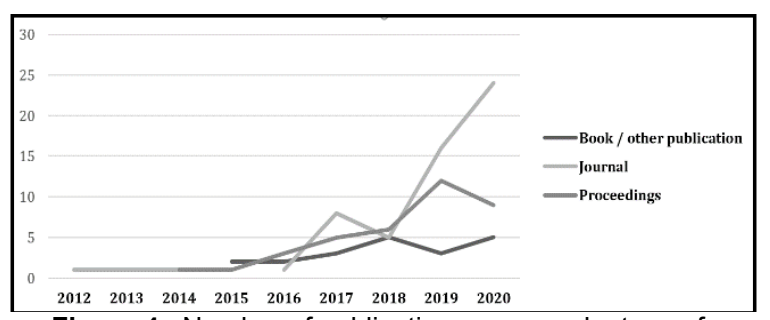

Figure 4 Number of publications per year by type of publication

Source: the authors

We grouped the publications into four main categories of research type: theoretical publications, systematic literature reviews of the subject, exploratory and empirical research and case studies. More than half of the publications are theoretical as expected, but it is also interesting to note that empirical and exploratory research participates in more than a quarter of total papers (Figure 5).

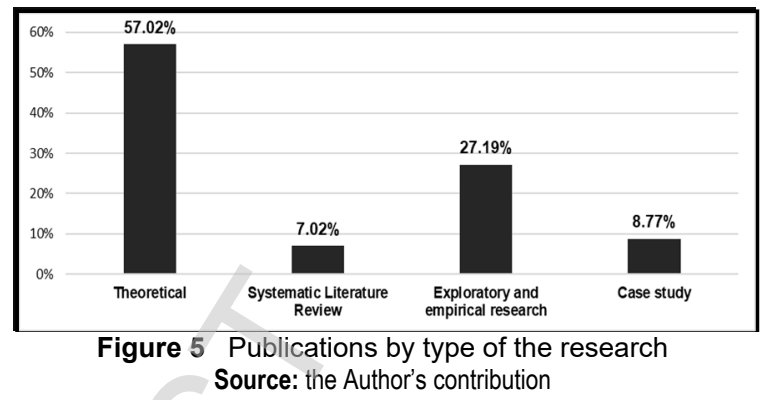

Analysis of the reviewed papers suggests that even if there is a high number of hits with digital workplace as part of their title, abstract or conclusion, only one third of them have strong focus on digital workplace as contemporary phenomena. Many publications, even if they have words "digital workplace" in the tittle, are only partly related to the subject of digital workplace transformation, which is definitely a limitation of the current state of research on this subject and suggests that this term is often misused.

\section{Further analysis and results}

\subsection{Research focus}

Topics of screened research papers are extremely varied. They range from digital workplace elements to different success factors of the transformation process.

Köffer (2015) provides a concise review of the literature on the digital workplace of the future in his study, focusing exclusively on leading journals and papers on topics related to collaboration, compliance, mobility and stress in the digital workplace. He also makes recommendations based on the literature within each of the four targeted digital workplace topics.

Attaran et al. (2019) focus on the changing nature of the workplace, emphasizing the importance of smart workplace technologies as well as identifying key determinants of the digital workplace implementation success.

The topics of the research are sometimes the types of digital workplace designs, i.e. identification of differences between those focused on people and those focused on processes or 
success of the different digital workplace models (Byström, Ruthven, \& Heinström, 2017; Lestarini, Raflesia, \& Surendro, 2016; Richter, Heinrich, Stocker, \& Schwabe, 2018; Schmidt, Praeg, \& Gunther, 2018; Williams \& Schubert, 2018; Zimmer, Baiyere, \& Salmela, 2020).

Research is sometimes focused on the importance of certain digital workplace transformation success factors, such as support of employees and their influence on the success itself. One of the papers examined the factors that lead employee support for digital transformation from the choice of technologies through organizational change to the design of the digital workplace itself (Meske \& Junglas, 2021).

Papers in the field of digital workplace design evaluation are focused on certain industries, such as small service businesses (Attaran et al., 2019) or wholesale (Meske \& Junglas, 2021). Some papers focus on the analysis of the data collected from a certain given set of companies: e.g., 13 companies in the analysis "Design for the Digital Workplace" by Williams and Schubert (2018). Research on digital transformation at the micro level focuses on individuals. Thus, a study investigating the impact of employee support on digital workplace transformation includes 150,000 respondents in a specific wholesale industry and is limited to Germany (Meske \& Junglas, 2021). Also, the focus of the research is limited to a selected set of companies and users of a particular software or system (Williams \& Schubert, 2018) or employees in one industry and one region e.g., employees in the wholesale trade in Germany (Meske \& Junglas, 2021).

Another topic of the research papers was the development of various models related to the digital workplace. Thus, Eckhardt et al. (2018) and others develop the so-called "Virtual Work Development Model" as a guide for companies striving for transition to a virtual workforce with the purpose of building a virtual workspace using easily accessible and highly effective technologies to regulate collaboration and communication between dislocated workers. The same group of authors, through their model, state that there are three types of readiness of employees for the transition to a virtual workplace: mental readiness, technological readiness and social readiness. Additionally, they provide overview questions to examine these types of readiness (Eckhardt et al., 2018)

One of the limitations of the current SLR is that they do not include papers from top ranked and indexed databases (such as WoS, Scopus, IEEE etc.). On the other hand, some SLR are exclusively based on papers from the leading databases but they include relatively insufficient numbers of papers (Köffer, 2015).

In addition to the usual keywords, such as digital workplace, digital transformation and collaboration, there are other keywords that are used in the publications: digital workplace design, user cases, enterprise, collaborative systems, company social software (Williams \& Schubert, 2018), compliance, mobility and stress (Köffer, 2015), workplace transformation, future of work, self-determination, change management, acceptance (Meske \& Junglas, 2021), collaborative learning, organizational accessibility etc. (Koles \& Nagy, 2014).

A group of papers analyzes global and regional changes of work and future trends of workplace (Burnett \& Lisk, 2019; Bygstad, Aanby, \& Iden, 2017; Cárdenas-García, Soria De Mesa, \& Romero Castro, 2019; Chopra \& Bhilare, 2020; Crooks et al., 2020; Darics \& Cristina Gatti, 2019; Egloffstein, 2018; Farrell, Newman, \& Corbel, 2021; Francis \& Scheers, 2013; Geng, Tan, Niu, Feng, \& Chen, 2019; Gerbaulet \& Korn, 2018; Hawkins \& Jacob, 2015; Ivaschenko, Simonova, Sitnikov, \& Shornikova, 2019; Köffer, 2015; Melzer \& Diewald, 2020; Odarenko, 2019; Okros, 2020; Poch et al., 2020; Schwarz et al., 2020; Seifert \& Nissen, 2018; Shivakumar, 2020; van Laar, van Deursen, van Dijk, \& de Haan, 2019; Vukelić \& Čizmić, 2019; Walker \& Lloyd-Walker, 2019; Willment, 2020; Yordanova, 2019; Yu, Burke, \& Raad, 2019) and another group of publications deals with education and upskilling as well as their influence to digital workplace transformation (Bartlett-Bragg, 2017; Brahma, Tripathi, \& Sahay, 2020; Harteis, 2018; Harteis, Goller, \& Caruso, 2020; Ifenthaler, 2018; Kayser, 2019; Montebello et al., 2019; Oberländer, Beinicke, \& Bipp, 2020; Pata \& Hirv, 2017; Phillips, 2016; Ravenscroft, Schmidt, Cook, \& Bradley, 2012; Rehe, Schneider, \& Thimm, 2020; Sarsar \& Yilmaz, 2018; Soon, Chiang, On, Rusli, \& Fun, 2020; Tripathy, 2019; van der Stappen \& Zitter, 2016; Wang, Chen, Yu, Huang, \& Chen, 2020; Zaphiris \& Ioannou, 2020).

Another group of publications focuses only on specific aspects or physical components of the workplace such are some hardware, ergonomics, communication technologies, gamification, virtual and augmented reality in workplace, knowledge management and knowledge recognition or work 
safety and health (Abdullah, 2018; Baptista, Stein, Klein, Watson-Manheim, \& Lee, 2020; de Souza Vianna, Leite, Butterworth, Taiar, \& Machado, 2020; Dodel \& Mesch, 2020; Englert, Woodcock, \& Cant, 2020; Ferreira, Araújo, Fernandes, \& Miguel, 2017; Garza, 2019; Hanafizadeh, Ghandchi, \& Asgarimehr, 2017; Hofma, Avital, Blegind Jensen, \& Hofma, 2017; Kim, Park, Jeong, Josue, \& Valdez, 2018; Koch, Yan, \& Curry, 2019; Kotsopoulos et al., 2017; Kuhlang et al., 2019; Lee et al., 2019; Li \& Herd, 2017; Mah et al., 2016; Meyer von Wolff et al., 2019; Meyer Von Wolff et al., 2020; Miele \& Tirabeni, 2020; Pompeii, 2020; Richardson, 2021; RodriguezBustelo et al., 2020; Shelton \& Smith, 2021; von Wolff et al., 2019; Zhang \& Leidner, 2014) or on importance of organizational factors such are management, human resources management, innovation management and employee acceptance for the success of digital workplace or its components (Bader \& Kaiser, 2017; Baptista et al., 2020; Dery et al., 2017; Dery \& Sebastian, 2017; Eckhardt et al., 2018; Fabbri, Mandreoli, Martoglia, \& Scapolan, 2019; Frank, Schmidt, Gimpel, \& Schoch, 2018; Genzorova, Corejova, \& Stalmasekova, 2019; Gerten, Beckmann, \& Bellmann, 2019; Greeven \& Williams, 2017; Haddud \& McAllen, 2018; Jarrahi \& Eshraghi, 2019; Kissmer, Knoll, Stieglitz, \& Gross, 2018; Kissmer, Potthoff, \& Stieglitz, 2018; Martensen et al., 2016; McParland \& Connolly, 2020; Meske, 2019; Meske et al., 2020; Meske \& Junglas, 2021; Nitschke et al., 2019; Oravec, 2020; Petersen, 2016; Richter \& Richter, 2020; Yalina \& Rozas, 2020; Zöller et al., 2020).

\subsection{Current definitions of digital workplace}

The term digital workplace was originally mentioned by Charles Grantham and Larry Nichols in 1993 (Grantham \& Nichol, 1993). Their understanding and definition of this concept was within the limits of technological and organizational development of the business at that time. In this paper they explain the link between technology, teamwork and business processes as well as their impact on customer satisfaction. They also state that companies can make the transition to a digital workplace as well as integrate advanced communication technologies into key business operations by overcoming obstacles to these changes. They pay special attention to management software and procedures that encourage the use of computers and telecommunications. Despite the fact that times in the early nineties were significantly different from today, it can be said that these two authors not only set the basic definition of the digital workplace but also predicted some of the trends and even pointed out the need for the companies and individuals to adapt to the digital transformation of business which to some extent had already begun (Grantham \& Nichol, 1993).

According to William and Shubert (2018) digital workplace characteristics are grouped into three basics headings, which could be a ground for establishing a comprehensive definition:

- Organizational strategy and digital workplace design;

This feature implies that the digital transformation of the workplace should be part of the overall organizational strategy and commitment to a new way of working, to enable the smooth establishment of a new work culture, to be a framework for designing and defining the development of technology platforms to support collaborative and flexible work, be futureoriented, adaptable and evolving in line with the development of technologies and labor legislation.

- Employees and work;

In short, digital workplace design should have the employee in focus and provide conditions for employees to be productive as well as to support the exchange of data, information and knowledge as well as to encourage employee engagement, collaboration and interaction.

- Technology platforms;

As an integrated platform, technology provides tools for the employees to be productive in doing their jobs. In addition, the mentioned platforms should be integrated into the overall information system of the company and independent of the location of the work, thus enabling flexible but integrated work of employees.

Current definitions of the digital workplace differ in the extent to which they are broader than the simple integration of the information technology.

Kissmer et al. (2018) state that "knowledge exchange, productivity and creativity are pillars of the digital workplace", without even mentioning technology or tools. 
The results of primary research on a larger sample of individuals indicate that the digital transformation of the workplace should be significantly broader than the acceptance of technology, i.e., it should enable the workforce to feel autonomous, competent and connected to others (Meske \& Junglas, 2021).

The business and the academy define the digital workplace in different ways. Intel defines technology, agile workplace, and collaboration as pillars of the digital workplace (Constant, 2017 as cited in Attran et al., 2019). Other sources and authors, according to the primary literature review by Attaran and others (2019), state that the digital workplace framework includes three building blocks: personal performance, team performance, and organizational performance that together provide an overview of all activities and projects.

A digital workplace is also defined as a holistic set of tools, platforms and workplaces, delivered in an applicable and productive way but also as a set of technologies that employees use to perform tasks in their workplace (Williams \& Schubert, 2018b).

The digital workplace can also be defined as a phenomenon in which new technologies cause significant changes in a wide range of aspects related to work: changes in the way employees perform work, changes in employee work processes and changes in their social relationships in the organization to a gradual change in overall work experience (Meske \& Junglas, 2021).

Attaran and others (2019) define digital workplace as a collection of the tools in an organization that enable employees to perform their tasks. The above mentioned tools include intranet, communication tools, email, CRM, ERP, HR systems, calendar and other corporate tools that help in the general daily functioning of the business. The digital workplace affects the physical workspace, technology and people.

Some authors also state that the digital workplace is a significant organizational resource for optimizing employee productivity based on knowledge as well as enabling new more effective ways of working (Köffer, 2015).

William and Schubert (2018) define a digital workplace as an integrated technology platform that provides all tools and services to employees to efficiently perform their work, independently or in collaboration with others, regardless of where they are located whereas all are strategically and organizationally coordinated through digital workplace design. to meet future organizational requirements and technologies.

The way of doing business in the last twenty years has changed significantly and is oriented towards digitalization and digital transformation (Kahrović \& Avdović, 2021). An increasing number of projects, communications and daily operational work are performed digitally using modern tools and technologies. Certainly, the digital transformation of the workplace is far more than the tools themselves and implies organizational, strategic and process changes in order to increase the efficiency and effectiveness of the modern workplace. Office documents and projects have largely gone online and instant messaging systems and email have become a popular communication choice for business correspondence.

There are three main trends that have influenced the establishment and definition of the digital workplace (Attaran et al., 2019):
Clutter
information
(Information
overload): The amount of information is growing exponentially and finding, filtering and forwarding of information is much more difficult,
- The need for higher speed: The modern workplace is changing significantly faster than before and employees are expected to work faster, collaborate and be more effective and efficient in their work,
- Workforce Demographics: Businesses face the challenge of meeting the changing demands of a multigenerational workforce and different generational groups: on the one hand, baby boomers retire and on the other, millennials are IT enthusiasts who expect flexible working hours and simple tools.

Intel defines several segments and phases of establishing a digital workplace. Below are the parts and phases listed by Constant (2017 2017 as cited in Attran et al., 2019):

- Physical transformation of the working place - agile workplace

The author states that traditional offices and workplaces are often expensive, inefficient, inflexible and challenging for scaling and modification, and therefore it is necessary to focus on an integrated platform with front and backoffice tools.

The author states that the digital workplace should satisfy the following criteria: characteristics 
of the digital place (which can be different, from the so-called home office, coworking space to third places) which implies easy access, portability, the possibility of continuous operation of the organization in one region or globally and the ability to work outside of corporate constraints; and the characteristics of a distributed early workplace which implies the fact that the workplace is no longer just a physical office space but a combination of physical, virtual, social and mental space that intertwine with the aim of creating a collaborative workplace.

- Solutions in the field of digital technologies

The author notes the importance of the existence of appropriate technologies and IT infrastructure designed and delivered by functional teams with the aim of repairing systems and improving organizational network infrastructure to every switch, router and firewall as well as appropriate software solutions from system to application. This part of the digital workplace includes the selection of cloud technology, big data analytics and similar segments of the application of digital technologies in the work and improvement of work

- Collaboration in the workplace

Here, the author states the need for platforms for knowledge sharing, especially in the segment of problem solving in dislocated locations, but also the choice of communication channels for company employees, which includes: collaboration platform, social networking tools, corporate intranet and public internet. Also, there is the unquestionable importance of virtualization and virtualization of work as well as enabling work on different devices and technologies of users.

Two categories of digital workplace design are identified: the one focused on people and the one focused on processes. Table 3 below is an illustration of the characteristics of each of these two focuses (Williams \& Schubert, 2018):

Table 3 Digital workplace design - features and uses

\begin{tabular}{l|l}
\hline $\begin{array}{l}\text { Focus on People } \\
\text { Information and Knowledge } \\
\text { Management }\end{array}$ & $\begin{array}{l}\text { Focus on Processes } \\
\text { Business Process Support }\end{array}$ \\
\hline Networked company platform & $\begin{array}{l}\text { Multifunctional integrated } \\
\text { platform }\end{array}$ \\
\hline Solution: portal & $\begin{array}{l}\text { Effective tool for business } \\
\text { processes }\end{array}$ \\
\hline $\begin{array}{l}\text { Exchange of information and } \\
\text { documents }\end{array}$ & Project support \\
\hline $\begin{array}{l}\text { Focus: } \\
\text { Content and communication }\end{array}$ & $\begin{array}{l}\text { Focus: } \\
\text { Processes and coordination }\end{array}$ \\
\hline & Source: Williams \& Schubert, 2018
\end{tabular}

The digital workplace is interpreted and designed in different ways by different organizations to meet different organizational requirements and expectations. These differences may depend on the business sector, the historical development of the company, but also on the nature of the implementation of a particular chosen solution. As such, the next step should include research into differences in definition and the factors that lead to differences in a deeper way in order to understand the digital-transformative character of the workplace (Williams \& Schubert, 2018).

A modern workplace should provide employees with a continuous experience as if they were clients of the company, i.e., the employee feels at all times as a factor of success of the company and not as a mere executor of work. Leaders expect their digital workplace (Attaran et al., 2019) to:

- raise employee engagement,

- enable employees to achieve business results faster, and

- encourage employees to lower costs and increase work efficiency.

The digital workplace, among other things, enables employees to successfully perform their tasks through appropriate platforms, software and devices. Digital workplace is alternative model of working which improves employees' performance, agility, productivity, collaboration and engagement as well as work-life balance (Dery \& Sebastian, 2017; Meske \& Junglas, 2021; Haddud \& McAllen, 2018).

Additionally, in the report (Deloitte, 2016), the digital workplace encompasses more than tools or a virtual office and presents a framework that includes the following four components:

1. Benefit and use: collaboration, communication and connection; Productive business connections within natural working groups that enable knowledge sharing throughout the organization;

2. Technology: a set of digital tools; The key is in embracing the right tools for employees to perform their assigned tasks efficiently;

3. Control: management, risk and compliance; The flow of information and its use must be harmonized with the organizational policies and legal regulations of a particular industry; 
4. Business drivers: measurable business values; The direction of the organization should be a guide and direction for the digital workplace.

Digital workplace brings specific challenges and it can fragment work but it also enables employees to enjoy technological contribution to collaboration and cooperation among employees, sometimes distant and in different time zones (Brahma et al., 2020).

One of the basic positive effects of establishing a comprehensive digital workplace is minimizing the so-called "time wasters" (Attaran et al., 2019):

- ineffective meetings, because meetings cost money and any waste of time through ineffective meetings leads to economic costs;

- email management, because employees spend a lot of time reading, replying and sorting emails, so spending time on these tasks is also spending money on organization;

- searching for information and people as a cost to the organization and a significant waste of time;

- duplicating work as a redundant activity that involves performing the same task multiple times or repeating a process previously repeated in another task or activity.

Research also shows that flexible working hours and a digital workplace have a positive effect on workers' absence, including less absence due to health problems, less depression in workers, less sleep problems and lower levels of stress The most significant advantage of creating a digital workplace is to improve worker productivity accompanied by worker satisfaction, improved worker experience and increased collaboration among workers, reduced operating costs, increased innovation, improved customer experience and ultimately increased revenue (Attaran et al., 2019).

\subsection{Future research recommendations by researchers}

Previous research suggests that the future focus of theory and practice of digital workplace transformation should be on the identification of the enabling and limiting effects of digital tools and to explore empirical evidence of the success of digital workplace implementation in a variety of organizations.
Meske and Junglas (2021) point out that future research should also focus on the micro level of digital transformation in order to identify the impact of digital transformation workplace and associated routine operations as well as negative effects at the micro level and their impact on worker satisfaction, such as the so-called negativity and technological stress.

In addition, it would be useful to investigate organizational and psychological factors due to extensive exposure to virtual workplaces that may directly or indirectly affect organization and digital transformation with special reference to the lack of face-to-face communication. Also, employee motivation as a factor in accepting the elements of digital workplace transformation requires additional research through case studies and empirical research (Koles \& Nagy, 2014).

Some studies indicate the reasons for the lack of effective use of the digital workplace by employees, which may be further investigated in the future because the observed shortcomings are mostly related to the application part of the digital workplace (Attaran et al., 2019), namely:

- challenges and difficulties of applying to different applications;

- inability to access data and applications in and out of the office; and

- need for help in accessing data.

The four primary characteristics of the digital workplace - collaboration, compliance, mobility, stress reduction and minimization of the so-called "waste" in the organization - are research areas of Köffer (2015), who in his work on digital space design, explores the above characteristics and, through the categorization of practical impacts, develops fifteen related concepts as useful tools for digital workplace design by professionals in the future. However, as the author himself states, his study is limited to selected top works and the mentioned concepts and recommendations in workplace design should be expanded, either by consulting additional literature or by consulting specific domain experts from the digital transformation of certain specific activities.

Additionally, there is no uniform definition of the term digital workplace and not only a large number of companies but also researchers foster the misleading belief that simple tools like email and social networks can be considered as a digital workplace. 


\subsection{Limitations of the current research}

Most of the current research in the domain of digital workplace transformation have identified limitation as a part their publications. Some of the authors focus exclusively on a limited number of companies or on a specific industry. Thus, one of the most specialized papers on the topic of digital workplace is focused on the success of digital workplace implementation in small service companies (e.g., Attaran et al., 2019) or they focus only on selected companies (Eckhardt et al., 2018).

Some authors, such as Köffer (2015), focus exclusively on selected top journals and use this as a basis for their proposals, which, regardless of quality, are based on a relatively small sample of consulted literature from exclusively leading journals and as such require additions or extensions. The largest available literature review, according to Attaran et al. (2019), cites forty-six sources of literature but mostly coming outside referent bibliographic databases (such are Web of Science or Scopus), including some web sources, reports and other sources. Additionally, the authors use limited and unreliable sources from various websites that are often the attitude of individuals and can hardly be considered valid scientific sources. In addition, reports and corporate sources have been used as literature, which can often have a hidden agenda or the promotion of certain products or tools that can be used to establish a digital workplace.

Research related to individuals and their relationship to digital transformation is often focused on a smaller group or even just one company, which is a significant limiting factor in drawing conclusions and research recommendations.

\subsection{Future research recommendation}

There is a well-justified need for further research of digital workplace transformation. This subject has an increased presence after COVID-19 pandemic and almost every sector, including the public, private, for profit or not for profit sectors have been affected with significant changes in the way of doing everyday work. Current research publications emphasize that it is not only a technological change that is present, such as use of specific tools but also there is organizational and management change that have an important role in the transformation process.

Future research should focus on specific sectors and industries that might be a business, industry or a specific sector such as public administration, education or healthcare which are all strongly affected by latest changes. Additionally, it would be useful to develop a separate, unique framework for digital workplace implementation for each of the industries in order to explain the transformation process from its own specific viewpoint.

\section{Conclusion and working definition of the digital workplace}

Workplace is transforming from so-called traditional to digital, not waiting for individuals and organizations to be completely ready. Therefore, the need for focused research in this field is important not just from a scientific point of view but also based on business needs for adjustment to the new normal. In order to achieve successful digital workplace transformation, an organization should have adequate transformation strategy as well as precisely identified expected outcomes and benefits for the organization. It should be also accompanying regulation of the following processes and procedures in order to achieve the goals.

Digital workplace transformation is a multistep process of transition from traditional workplace, usually considered as a physically limited space and set of correlated tasks, to digital workplace, which is more flexible regarding place and time of work, and supported through adequate strategic and technological background.

Therefore, we can define digital workplace as digital technology-supported working system consisted of, not only the physical space, employees and tasks, but also set of strategically accepted procedures and rules in order to maximize productivity and improve collaboration, communication and knowledge management.

However, each industry or a specific profession requires its own adjustment of the definition and separate focused framework development in order to maximize benefits of the digital workplace transformation.sM

\section{References}

Abdullah, N. (2018). Preface. In Communications in Computer and Information Science (Vol. 886). Springer Singapore.

https://doi.org/10.1007/978-981-13-1628-9

Attaran, M., Attaran, S., \& Kirkland, D. (2019). The need for digital workplace: Increasing workforce productivity in the information age. International Journal of Enterprise Information Systems, 15(1), 1-23. https://doi.org/10.4018/IJEIS.2019010101 
Bader, V., \& Kaiser, S. (2017). Autonomy and control? How heterogeneous sociomaterial assemblages explain paradoxical rationalities in the digital workplace. Management Revu, 28(3), 338-358. https://doi.org/10.5771/0935-9915-2017-3-338

Baptista, J., Stein, M. K., Klein, S., Watson-Manheim, M. B., \& Lee, J. (2020). Digital work and organisational transformation: Emergent digital/human work configurations in modern organisations. Journal of Strategic Information Systems, 29(2), 1-10. https://doi.org/10.1016/j.jsis.2020.101618

Bartlett-Bragg, A. (2017). Digital capabilities: Where people and technology intersect. EDULEARN17 Proceedings, 1(July), 14-21. https://doi.org/10.21125/edulearn.2017.1004

Brahma, M., Tripathi, S. S., \& Sahay, A. (2020). Developing curriculum for industry 4.0: digital workplaces. Higher Education, Skills and Work-Based Learning. https://doi.org/10.1108/HESWBL-08-2019-0103

Burnett, J. R., \& Lisk, T. C. (2019). The future of employee engagement: Real-time monitoring and digital tools for engaging a workforce. International Studies of Management and Organization, 49(1), 108-119. https://doi.org/10.1080/00208825.2019.1565097

Bygstad, B., Aanby, H. P., \& Iden, J. (2017). Leading digital transformation: The Scandinavian way. Lecture Notes in Business Information Processing, 294(16), 1-14. https://doi.org/10.1007/978-3-319-64695-4 1

Byström, K., Ruthven, I., \& Heinström, J. (2017). Work and information: Which workplace models still work in modern digital workplaces? Information Research, 22(1).

Cárdenas-García, J. F., Soria De Mesa, B., \& Romero Castro, D. (2019). Understanding Globalized digital labor in the information age. Perspectives on Global Development and Technology, 18(3), 308-326. https://doi.org/10.1163/15691497-12341519

Grantham, C. E., \& Nichol, L. D. (1993). The Digital Workplace: Designing Groupware Platforms (Vnr Computer Library). Van Nostrand Reinhold.

Chopra, A., \& Bhilare, P. (2020). Future of work: An Empirical study to understand expectations of the millennials from organizations. Business Perspectives and Research, 8(2), 272-288. https://doi.org/10.1177/2278533719887457

Coetzee, M. (2019). Thriving in Digital Workspaces: An Introductory Chapter. In Thriving in Digital Workspaces (pp. 1-11). Springer International Publishing. https://doi.org/10.1007/978-3-030-24463-7 1

Crooks, C. L., Hogg, J. L., Martin, S. M., Grant, J., Lemoie, K., \& Robbins, M. (2020). Understanding Generational Factors in the Workplace: Current Considerations for Telework Practices and the Digital Native. 168-172. https://doi.org/10.1109/procomm48883.2020.00033

Darics, E., \& Cristina Gatti, M. (2019). Talking a team into being in online workplace collaborations: The discourse of virtual work. Discourse Studies, 21(3), 237-257. https://doi.org/10.1177/1461445619829240

de Souza Vianna, B. E., Leite, P. K. R., Butterworth, E., Taiar, R., \& Machado, C. B. (2020). Preliminary Results on the Assessment of Temperature Distribution on Hands After Typing on Ergonomic and Non-ergonomic Postures. In T. Ahram, R. Taiar, S. Colson, \& A. Choplin (Eds.), Human Interaction and Emerging Technologies. IHIET 2019. Advances in Intelligent Systems and Computing, vol 1018. (pp. 586-591). https://doi.org/10.1007/978-3-030-25629-6 91
Deloitte. (2016). How digital technologies are changing the workforce and how enterprises can adapt and evolve. Digital Workplace and Culture. Retreived September 1, 2020, from https://www2.deloitte.com/content/dam/Deloitte/us/Docu ments/human-capital/us-cons-digital-workplace-andculture.pdf

Dery, K., \& Sebastian, I. M. (2017). Managing talent for digital. AMCIS 2017 - America's Conference on Information Systems: A Tradition of Innovation, 2017Augus, 1-5.

Dery, K., Sebastian, I. M., \& van der Meulen, N. (2017). The digital workplace is key to digital innovation. MIS Quarterly Executive, 16(2), 135-152.

Dodel, M., \& Mesch, G. S. (2020). Perceptions about the impact of automation in the workplace. Information Communication and Society, 23(5), 665-680. https://doi.org/10.1080/1369118X.2020.1716043

Eckhardt, A., Endter, F., Giordano, A., \& Somers, P. (2018). Three stages to a virtual workforce. MIS Quarterly Executive, 18(1), 19-35. https://doi.org/10.17705/2msqe.00006

Egloffstein, M. (2018). Massive open online courses in digital workplace learning: Current state and future perspectives. Digital Workplace Learning: Bridging Formal and Informal Learning with Digital Technologies, 149-166. https://doi.org/10.1007/978-3-319-46215-8 9

Englert, S., Woodcock, J., \& Cant, C. (2020). Digital Workerism: Technology, Platforms, and the Circulation of Workers' Struggles. TripleC: Communication, Capitalism \& Critique. Open Access Journal for a Global Sustainable Information Society, 18(1), 132145. https://doi.org/10.31269/triplec.v18i1.1133

Fabbri, T., Mandreoli, F., Martoglia, R., \& Scapolan, A. C. (2019). Employee attitudes and (digital) collaboration data: a preliminary analysis in the HRM field. Proceedings - International Conference on Computer Communications and Networks, ICCCN, 2019-July, 16. https://doi.org/10.1109/ICCCN.2019.8846957

Farrell, L., Newman, T., \& Corbel, C. (2021). Literacy and the workplace revolution: a social view of literate work practices in Industry 4.0. Discourse: Studies in the Cultural Politics of Education, 42(6), 898-912. https://doi.org/10.1080/01596306.2020.1753016

Ferreira, A. T., Araújo, A. M., Fernandes, S., \& Miguel, I. C. (2017). Gamification in the workplace: a systematic literature review. Advances in Intelligent Systems and Computing, 571, 283-292. https://doi.org/10.1007/978-3-319-56541-5 29

Francis, J., \& Scheers, C. (2013). The future workplace of young Europeans. European View, 12(2), 199-204. https://doi.org/10.1007/s12290-013-0286-y

Frank, L., Schmidt, M., Gimpel, H., \& Schoch, M. (2018). Emergent user roles of a digital workplace: a network analysis based on trace data. ICIS 2017: Transforming Society with Digital Innovation.

Garza, A. (2019). H. A. McKee and J. E. Porter: Professional Communication and network interaction: a rhetorical and ethical approach. IEEE Transactions on Professional Communication, 62(3), 312-313. https://doi.org/10.1109/TPC.2019.2922723 
Geng, S., Tan, L., Niu, B., Feng, Y., \& Chen, L. (2019). Knowledge recommendation for workplace learning: a system design and evaluation perspective. Internet Research, 30(1), 243-261. https://doi.org/10.1108/INTR-07-2018-0336

Genzorova, T., Corejova, T., \& Stalmasekova, N. (2019). How digital transformation can influence business model, case study for transport industry. Transportation Research Procedia, 40, 1053-1058. https://doi.org/10.1016/j.trpro.2019.07.147

Gerbaulet, D., \& Korn, O. (2018). Do zenware applications reduce the digital distraction of knowledge workers? A qualitative study based on expert interviews. Advances in Intelligent Systems and Computing, 588, 115-126. https://doi.org/10.1007/978-3-319-60582-1 12

Gerten, E., Beckmann, M., \& Bellmann, L. (2019). Controlling working crowds: the impact of digitalization on worker autonomy and monitoring across hierarchical levels. Jahrbucher Fur Nationalokonomie Und Statistik, 239(3), 441-481.

https://doi.org/10.1515/jbnst-2017-0154

Greeven, C. S., \& Williams, S. P. (2017). Enterprise collaboration systems: Addressing adoption challenges and the shaping of sociotechnical systems. International Journal of Information Systems and Project Management, 5(1), 5-23. https://doi.org/10.12821/ijispm050101

Haddud, A., \& McAllen, D. (2018). Digital workplace management: Exploring aspects related to culture, innovation, and leadership. PICMET 2018 - Portland International Conference on Management of Engineering and Technology: Managing Technological Entrepreneurship: The Engine for Economic Growth, Proceedings, 1-6. https://doi.org/10.23919/PICMET.2018.8481807

Hanafizadeh, P., Ghandchi, S., \& Asgarimehr, M. (2017). Impact of Information Technology on Lifestyle. International Journal of Virtual Communities and Social Networking, 9(2), 1-23. https://doi.org/10.4018/IJVCSN.2017040101

Harteis, C. (2018). Professional and Practice-based learning. The Impact of Digitalization in the Workplace An Educational View. https://doi.org/10.1007/978-3-319-63257-5

Harteis, C., Goller, M., \& Caruso, C. (2020). Conceptual Change in the face of digitalization: challenges for workplaces and workplace learning. Frontiers in Education, 5(January), 1-10. https://doi.org/10.3389/feduc.2020.00001

Neubauer, D. E., \& Ghazali, K. (Eds.). (2015). Technology and Workplace Skills for the Twenty-First Century. Palgrave Macmillan US. https://doi.org/10.1057/9781137491923

Hofma, C. C., Avital, M., Blegind Jensen, T., \& Hofma, C. (2017). Liquid Workplaces: The Potential Implications of Virtual Reality on the Workplace Liquid Workplaces: The Potential Implications of Virtual Reality on the Workplace. Association for Information Systems AIS Electronic Library (AISeL) 8(9).

Ifenthaler, D. (2018). How We Learn at the Digital Workplace. In Digital Workplace Learning (pp. 3-8). Springer International Publishing. https://doi.org/10.1007/978-3-319-46215-8 1

Ivaschenko, A. V., Simonova, M. V., Sitnikov, P. V., \& Shornikova, O. V. (2019). Big Data Analysis For $\mathrm{Hr}$ Management At Production Enterprises. In V. Mantulenko (Ed.), Global Challenges and Prospects of the Modern Economic Development, vol 57. European Proceedings of Social and Behavioural Sciences (pp. 463-471). Future Academy.

https://doi.org/10.15405/epsbs.2019.03.46

Jarrahi, M. H., \& Eshraghi, A. (2019). Digital natives vs digital immigrants: a multidimensional view on interaction with social technologies in organizations. Journal of Enterprise Information Management, 32(6), 1051-1070. https://doi.org/10.1108/JEIM-04-2018-0071

Kahrović, E., \& Avdović, A. (2021). Impact of Digital Technologies on Business Performance in Serbia. Management:Journal of Sustainable Business and Management Solutions in Emerging Economies. https://doi.org/10.7595/management.fon.2021.0039

Kayser, I. (2019). Digitale Transformation: Veränderung der Arbeitswelt erfordert Anpassung der Qualifikation. B\&G Bewegungstherapie Und Gesundheitssport, 35(3), 158160. https://doi.org/10.1055/a-0890-8557

Kim, S. J., Park, S. J., Jeong, Y., Josue, J., \& Valdez, M. (2018). The AR Strip: A City Incorporated Augmented Reality Educational Curriculum. In N. Streitz \& S. Konomi (Eds.), Distributed, Ambient and Pervasive Interactions: Understanding Humans. DAPI 2018. Lecture Notes in Computer Science, vol 10921. (pp. 85-90). https://doi.org/10.1007/978-3-319-91125-0 6

Kissmer, T., Knoll, J., Stieglitz, S., \& Gross, R. (2018). Knowledge workers' expectations towards a digital workplace. America's Conference on Information Systems 2018: Digital Disruption, AMCIS 2018, July.

Kissmer, T., Potthoff, T., \& Stieglitz, S. (2018). Enterprise Digital Nudging: Between Adoption Gain and Unintended Rejection. Americas Conference on Information Systems (AMCIS), July.

Kitchenham, B., Pearl Brereton, O., Budgen, D., Turner, M., Bailey, J., \& Linkman, S. (2009). Systematic literature reviews in software engineering - a systematic literature review. Information and Software Technology, 51(1), 715. https://doi.org/10.1016/j.infsof.2008.09.009

Kitchenham, B., Pretorius, R., Budgen, D., Brereton, O. P., Turner, M., Niazi, M., \& Linkman, S. (2010). Systematic literature reviews in software engineering-A tertiary study. Information and Software Technology, 52(8), 792-805.

https://doi.org/10.1016/j.infsof.2010.03.006

Koch, H., Yan, J., \& Curry, P. (2019). Consumerizationconflict resolution and changing IT-user relationships. Information Technology and People, 33(1), 251-271. https://doi.org/10.1108//TP-11-2017-0411

Köffer, S. (2015). Designing the digital workplace of the future - what scholars recommend to practitioners. 2015 International Conference on Information Systems: Exploring the Information Frontier, ICIS 2015, 1-21.

Koles, B., \& Nagy, P. (2014). Virtual worlds as digital workplaces. Organizational Psychology Review, 4(2), 175-195. https://doi.org/10.1177/2041386613507074

Kotsopoulos, D., Bardaki, C., Lounis, S., Papaioannou, T., \& Pramatari, K. (2017, June). Designing an loT-enabled Gamification Application for Energy Conservation at the Workplace: Exploring Personal and Contextual Characteristics. Digital Transformation - From Connecting Things to Transforming Our Lives. https://doi.org/10.18690/978-961-286-043-1.26 
Kuhlang, P., Ostermeier, M., \& Benter, M. (2019). Human Work Design: Modern Approaches for Designing Ergonomic and Productive Work in Times of Digital Transformation - An International Perspective. In S. Bagnara, R. Tartaglia, S. Albolino, T. Alexander, \& Y. Fujita (Eds.), Proceedings of the 20th Congress of the International Ergonomics Association (IEA 2018). IEA 2018. Advances in Intelligent Systems and Computing, vol 825. (pp. 29-37).

https://doi.org/10.1007/978-3-319-96068-5 4

Lee, J., Andersen, K. N., \& Henriksen, H. Z. (2019). Impact of IT in the public sector workplace. ACM International Conference Proceeding Series, 370-377. https://doi.org/10.1145/3325112.3325216

Lestarini, D., Raflesia, S. P., \& Surendro, K. (2016). A conceptual framework of engaged digital workplace diffusion. Proceeding of the 2015 9th International Conference on Telecommunication Systems Services and Applications, TSSA 2015, January 2018. https://doi.org/10.1109/TSSA.2015.7440431

Li, J., \& Herd, A. M. (2017). Shifting practices in digital workplace learning: An integrated approach to learning, knowledge management, and knowledge sharing. Human Resource Development International, 20(3), 185-193. https://doi.org/10.1080/13678868.2017.1308460

Mah, D. K., Bellin-Mularski, N., \& Ifenthaler, D. (2016). Foundation of digital badges and micro-credentials: Demonstrating and recognizing knowledge and competencies. Foundation of Digital Badges and MicroCredentials: Demonstrating and Recognizing Knowledge and Competencies, 1-530. https://doi.org/10.1007/978-3-319-15425-1

Martensen, M., Ryschka, S., Blesik, T., \& Bick, M. (2016). Collaboration in the consulting industry: Analyzing differences in the professional use of social software. Business Process Management Journal, 22(4), 693 711. https://doi.org/10.1108/BPMJ-06-2015-0093

McParland, C., \& Connolly, R. (2020). Dataveillance in the workplace: Managing the impact of innovation. Business Systems Research, 11(1), 106-124. https://doi.org/10.2478/bsrj-2020-0008

Melzer, S. M., \& Diewald, M. (2020). How individual involvement with digitalizedwork and digitalization at the workplace level impacts supervisory and coworker bullying in German workplaces. Social Sciences, 9(9). https://doi.org/10.3390/SOCSCI9090156

Meske, C. (2019). Digital workplace transformation - on the role of self-determination in the. ECIS 2019 Proceedings, May, 2-8.

Meske, C., \& Junglas, I. (2021). Investigating the elicitation of employees' support towards digital workplace transformation. Behaviour \& Information Technology, 40(11), 1120-1136. https://doi.org/10.1080/0144929X.2020.1742382

Meske, C., Kissmer, T., \& Stieglitz, S. (2020). Bridging formal barriers in digital work environments Investigating technology-enabled interactions across organizational hierarchies. Telematics and Informatics, 48(October 2019), 101342. https://doi.org/10.1016/j.tele.2020.101342

Meyer Von Wolff, R., Hobert, S., Masuch, K., \& Schumann, M. (2020). Chatbots at digital workplaces - a groundedtheory approach for surveying application areas and objectives. Pacific Asia Journal of the Association for Information Systems, 12(2), 64-102. https://doi.org/10.17705/1pais.12203
Meyer von Wolff, R., Hobert, S., \& Schumann, M. (2019). How may I help you? - State of the art and open research questions for chatbots at the digital workplace. Proceedings of the 52nd Hawaii International Conference on System Sciences, 6, 95-104. https://doi.org/10.24251/hicss.2019.013

Miele, F., \& Tirabeni, L. (2020). Digital technologies and power dynamics in the organization: a conceptual review of remote working and wearable technologies at work. Sociology Compass, 14(6), 1-13. https://doi.org/10.1111/soc4.12795

Montebello, M., Cope, B., Kalantzis, M., Amina, T., Searsmith, D., Tzirides, A., \& Haniya, S. (2019). Deepening e-learning through social-collaborative intelligence. Proceedings - Frontiers in Education Conference, FIE, 2018-Octob, 1-4. https://doi.org/10.1109/FIE.2018.8658779

Nitschke, C. S., Williams, S. P., \& Schubert, P. (2019). A multiorganisational study of the drivers and barriers of enterprise collaboration systems-enabled change. International Conference on Wirtschaftsinformatik (WI), February.

Oberländer, M., Beinicke, A., \& Bipp, T. (2020). Digital competencies: A review of the literature and applications in the workplace. Computers and Education, 146, 103752. https://doi.org/10.1016/j.compedu.2019.103752

Odarenko, T. Y. (2019). Perspectives of digitization in staff management. CEUR Workshop Proceedings, 2522, 121-130.

Okros, A. (2020). Harnessing the Potential of Digital PostMillennials. In Harnessing the Potential of Digital PostMillennials in the Future Workplace. Management for Professionals (pp. 155-169). https://doi.org/10.1007/978-3-030-25726-2 8

Oravec, J. A. (2020). Digital iatrogenesis and workplace marginalization: some ethical issues involving selftracking medical technologies. Information, Communication \& Society, 23(14), 2030-2046. https://doi.org/10.1080/1369118X.2020.1718178

Pata, K., \& Hirv, J. (2017). Digital workers' preferences towards the informal learning ecosystem for distributed workplaces. Communications in Computer and Information Science, 734, 185-197. https://doi.org/10.1007/978-3-319-62743-4 16

Petersen, E. J. (2016). Reterritorializing workspaces: Entrepreneurial podcasting as situated networking, connected mediation, and contextualized professionalism. IEEE International Professional Communication Conference, 2016-Novem. https://doi.org/10.1109/IPCC.2016.7740516

Phillips, M. (2016). Digital technology, schools and teachers' workplace learning. In Digital Technology, Schools and Teachers' Workplace Learning. https://doi.org/10.1057/978-1-137-52462-1

Poch, M., Garrido-Baserba, M., Corominas, L., PerellóMoragues, A., Monclús, H., Cermerón-Romero, M., Melitas, N., Jiang, S. C., \& Rosso, D. (2020). When the fourth water and digital revolution encountered COVID19. Science of the Total Environment, 744, 140980. https://doi.org/10.1016/j.scitotenv.2020.140980

Pompeii, L. (2020). Workplace health \& safety is going digital! Workplace Health and Safety, 68(1), 5. https://doi.org/10.1177/2165079919892628 
Ravenscroft, A., Schmidt, A., Cook, J., \& Bradley, C. (2012). Designing social media for informal learning and knowledge maturing in the digital workplace. Journal of Computer Assisted Learning, 28(3), 235-249. https://doi.org/10.1111/j.1365-2729.2012.00485.x

Rehe, G., Schneider, R., \& Thimm, D. D. (2020). Transformation towards human workforce 4.0 through the qualification model LTA-FIT. Proceedings of the 53rd Hawaii International Conference on System Sciences, 3, 4601-4610. https://doi.org/10.24251/hicss.2020.563

Richardson, L. (2021). Coordinating office space: Digital technologies and the platformization of work. Environment and Planning D: Society and Space, 39(2), 347-365. https://doi.org/10.1177/0263775820959677

Richter, A., Heinrich, P., Stocker, A., \& Schwabe, G. (2018). digital work design: the interplay of human and computer in future work practices as an interdisciplinary (Grand) Challenge. Business and Information Systems Engineering, 60(3), 259-264. https://doi.org/10.1007/s12599-018-0534-4

Richter, S., \& Richter, A. (2020). Digital nomads. Business and Information Systems Engineering, 62(1), 77-81. https://doi.org/10.1007/s12599-019-00615-1

Rodriguez-Bustelo, C., Batista-Foguet, J. M., \& Serlavós, R. (2020). Debating the future of work: the perception and reaction of the spanish workforce to digitization and automation technologies. Frontiers in Psychology, 11(August), 1-14. https://doi.org/10.3389/fpsyg.2020.01965

Sarsar, F., \& Yılmaz, Y. (2018). Designing Flipped Learning for Digital Workplace Learning. In D. Ifenthaler (Ed.), Digital Workplace Learning (pp. 93-106). Springer International Publishing. https://doi.org/10.1007/978-3-319-46215-8 6

Schmidt, C., Praeg, C. P., \& Gunther, J. (2018). Designing digital workplace environments. 2018 IEEE International Conference on Engineering, Technology and Innovation, ICE/ITMC 2018 - Proceedings, August 2019. https://doi.org/10.1109/ICE.2018.8436349

Schwarz, M., Scherrer, A., Hohmann, C., Heiberg, J., Brugger, A., \& Nuñez-Jimenez, A. (2020). COVID-19 and the academy: It is time for going digital. Energy Research and Social Science, 68(June). https://doi.org/10.1016/j.erss.2020.101684

Seifert, H., \& Nissen, V. (2018). Crowd Workplace-A Case Study on the Digital Transformation Within IT- and Management-Consulting. In V. Nissen (Ed.), Digital Transformation of the Consulting Industry (pp. 299321). https://doi.org/10.1007/978-3-319-70491-3 12

Shelton, C. L., \& Smith, A. F. (2021). Workplace distractions in the digital era - are smartphones a threat to safety or an essential tool? Anaesthesia, 76(3), 305-308. https://doi.org/10.1111/anae.15234

Shivakumar, S. K. (2020). Build a next-generation digital workplace. Apress.

https://doi.org/10.1007/978-1-4842-5512-4

Soon, G. K., Chiang, L. C., On, C. K., Rusli, N. M., \& Fun, T. S. (2020). Comparison of Ensemble Simple Feedforward Neural Network and Deep Learning Neural Network on Phishing Detection. In R. Alfred, Y. Lim, H. Haviluddin, \& C. On (Eds.), Computational Science and Technology. Lecture Notes in Electrical Engineering, vol 603. (pp. 595-604). https://doi.org/10.1007/978-981-15-0058-9 57
Tripathy, M. (2019). The role of professional skills in digital transformation for organisational effectiveness. International Journal of Scientific and Technology Research, 8(10), 498-501.

Turner, M., Kitchenham, B., Budgen, D., \& Brereton, P. (2008). Lessons learnt undertaking a large-scale systematic literature review. 12th International Conference on Evaluation and Assessment in Software Engineering, EASE 2008. https://doi.org/10.14236/ewic/ease2008.12

van der Stappen, E., \& Zitter, I. (2016). Exploring design principles for technology-enhanced workplace learning. 29th Bled EConference: Digital Economy, BLED 2016.

van Laar, E., van Deursen, A. J. A. M., van Dijk, J. A. G. M., \& de Haan, J. (2019). Determinants of 21st-century digital skills: a large-scale survey among working professionals. Computers in Human Behavior, 100(June), 93-104.

https://doi.org/10.1016/j.chb.2019.06.017

von Wolff, R. M., Masuch, K., Hobert, S., \& Schumann, M. (2019). What do you need today? - an empirical systematization of application areas for chatbots at digital workplaces. 25th Americas Conference on Information Systems, AMCIS 2019, August.

Vukelić, M., \& Čizmić, S. (2019). Employee wellbeing in the digital age. 2019 Zooming Innovation in Consumer Technologies Conference, ZINC 2019, 100-102. https://doi.org/10.1109/ZINC.2019.8769391

Walker, D., \& Lloyd-Walker, B. (2019). The future of the management of projects in the 2030s. International Journal of Managing Projects in Business, 12(2), 242266. https://doi.org/10.1108/IJMPB-02-2018-0034

Wang, J. H., Chen, Y. H., Yu, S. Y., Huang, Y. L., \& Chen, G. D. (2020). Digital learning theater with automatic instant assessment of body language and oral language learning. Proceedings - IEEE 20th International Conference on Advanced Learning Technologies, ICALT 2020, 218-222. https://doi.org/10.1109/ICALT49669.2020.00071

Williams, S. P., \& Schubert, P. (2018). Designs for the digital workplace. Procedia Computer Science, 138(November), 478-485. https://doi.org/10.1016/j.procs.2018.10.066

Willment, N. (2020). The travel blogger as digital nomad: $(\mathrm{Re}$-)imagining workplace performances of digital nomadism within travel blogging work. Information Technology \& Tourism, 22(3), 391-416. https://doi.org/10.1007/s40558-020-00173-3

Yalina, N., \& Rozas, I. S. (2020). Digital workplace: digital transformation for environmental sustainability. IOP Conference Series: Earth and Environmental Science, 456(1). https://doi.org/10.1088/1755-1315/456/1/012022

Yordanova, G. (2019). Global digital workplace as a potential for Bulgarian woman to achieve better work family balance. Revista Inclusiones, 6(SI), 248-264.

Yu, R., Burke, M., \& Raad, N. (2019). Exploring impact of future flexible working model evolution on urban environment, economy and planning. Journal of Urban Management, 8(3), 447-457. https://doi.org/10.1016/j.jum.2019.05.002

Zaphiris, P., loannou, A. (2020). Learning and Collaboration Technologies Designing, Developing and Deploying Lecture Notes in Computer Science. Springer Nature Switzerland AG. 
Zhang, S., \& Leidner, D. (2014). Workplace cyberbullying: The antecedents and consequences research-inprogress. 20th Americas Conference on Information Systems, AMCIS 2014, 2011, 1-11.

Zimmer, M. P., Baiyere, A., \& Salmela, H. (2020). Digital Workplace transformation: the importance of deinstitutionalising the taken for granted. European Conference on Information Systems (ECIS) 2020 Proceedings, June, 1-15.

\section{凶 Correspondence}

\section{Predrag Matković}

University of Novi Sad, Faculty of Economics in Subotica

Segedinski put 9-11, 24000 Subotica, Serbia

E-mail: predrag.matkovic@ef.uns.ac.rs
Zöller, N., Morgan, J. H., \& Schröder, T. (2020). A topology of groups: What GitHub can tell us about online collaboration. Technological Forecasting and Social Change, 161(August 2019).

https://doi.org/10.1016/j.techfore.2020.120291 